\title{
16
}

\section{Closing the Gap}

\begin{abstract}
In this concluding chapter Cilliers presents a combined Close the Gap scenario that integrates the eleven scenarios that were modelled in the previous chapters and compares the impact with the Current Path prospects on dimensions such as income growth, economic size, impact on extreme poverty and carbon emissions. The chapter then moves on to compare the impact of the scenarios with one another. The results differ for low, lowermiddle and upper-income countries as well as over time. The differences are illustrated with reference to improvements for each income group in 2030, 2040 and 2050. The chapter then sketches out a broad description of a 'standard economic growth model' that emerges from the preceding analysis. It concludes by pointing to the similarities and differences compared to China's recent history.
\end{abstract}

Keywords Economic growth · Africa - Health · Demographics . Demographic dividend · Basic infrastructure - Industrialisation . Manufacturing · Trade - African Continental Free Trade Area • Leapfrogging · Governance - External support · Trade - Remittances • Foreign direct investment - Peace - Good governance - Democracy · Trade integration · Jobs - Work - Social capital · Human capital · Multifactor productivity - Knowledge capital - Physical capital - Agriculture - Services . Scenarios · Forecasts · Poverty · Inequality · Income · Population - Carbon emissions . Climate change · Low-income countries - Lower-middle-income countries · Upper-middle-income countries · Value-add · Economic composition - Social grants - Inequality · Education - China - Innovation * Regional integration · Urbanisation 


\section{Learning Objectives}

- Understanding the contribution that improvements in basic infrastructure, demographics, agriculture, education, health, industrialisation, leapfrogging, increased trade, stability, democracy and external support could make to reductions in poverty, increases in income and inequality for low-, lower-middle and upper-middle-income countries in Africa

In this book, I have taken the reader on a journey across the improvements that are required to help close the growing income gap between Africa and the rest of the world. Figure 1.1 in Chapter 1 shows the extent to which the gap has grown incrementally with each passing decade since independence in the 1960s. The Current Path forecast is for that gap to continue to widen to 2040 and beyond.

Things are improving in Africa but it is happening at a slower pace than elsewhere. As a result, Africa is falling further and further behind on most averages of well-being compared to the rest of the world.

The 55 countries that collectively constitute Africa are expected to experience an average economic growth rate of $4.7 \%$ from 2020 to 2040 and the continent's economy will increase by more than $150 \%$ in size. But because Africa's population will have increased by almost $60 \%$ by then, Gross Domestic Product (GDP) per person (in purchasing power parity or PPP) will only increase by $35 \%$. Contrast that with the expected increase of more than $150 \%$ in the rest of the world! While it is still too early to factor in the impact that the COVID-19 pandemic will have on Africa and the global economy, it will inevitably be negative and likely further increase the challenge of catching up since Africa has less ability to cope with the associated effects.

To this end, the preceding chapters have looked at the impact of successive interventions that could reverse the trend of growing divergence, namely: Improved Health, achieving a Demographic Dividend; an African Agricultural Revolution; a Rejuvenation in Education; rolling out Social Grants for Africa; a manufacturing transition through the Made in Africa scenario; Leapfrogging through various technologies; trade integration through the implementation of the African Continental Free Trade Area; a rapid decline in violence and insecurity by Silencing the Guns; continuing progress as part of a Fourth Wave of Democracy; and gaining from External Support. 
I have taken care to benchmark the interventions used in each scenario to ensure the impact is aspirational but realistic. That benchmarking is available at www.jakkiecilliers.org and provides a degree of confidence that the scenarios represent levels of progress comparable to what has been historically achieved by countries at similar levels of development and that have done particularly well in a particular area.

In addition, two chapters reviewed the future of work in Africa and provided an overview of the effects of climate change. These two chapters compared the impact of some of the scenarios listed above with one another.

Forecasts and scenarios are not predictions and it is certain that the future will unfold quite differently to what is set out in this book. So-called Black Swan or unexpected, high-impact events, such as the COVID-19 pandemic, could temporarily derail trends but since the IFs system does its forecasts based on longitudinal trends, it bakes in some of the impact of unforeseen events. Eventually informed analysis of the future is simply much better than bumbling along blindly.

Although it is unlikely that all of Africa will be able to simultaneously advance on all eleven of these transitions in the section below I first present the impact of the Close the Gap scenario that includes a combined forecast of the impact of all eleven scenarios.

\section{Prospects in the Close the Gap Scenario}

When discussing the combined Close the Gap scenario, it is important to reemphasise that the IFs forecasting platform is highly integrated, meaning that improvements in education, for example, would positively impact on social capital (and hence economic growth) and therefore improve productivity in the Made in Africa scenario on manufacturing.

This holds true across various dimensions. It means that some improvements could have an unexpected or greater than foreseen impact, although it is equally true that some interventions also compete with each other. For example, while more social grants reduce poverty it eventually starts to detract from economic growth prospects although the relationship is complex. ${ }^{1} \mathrm{But}$ generally speaking, all good things come together in the Close the Gap scenario and the combined impact of the eleven positive scenarios present a step change in Africa's development prospects.

\footnotetext{
${ }^{1}$ On the other hand, over longer time horizons reductions in poverty would improve human capital and eventually have a positive impact upon economic growth.
} 


\section{GDP Per Capita in the Close the Gap Scenario}

Figure 16.1 presents the same information as presented in Fig. 1.1 in Chapter 1, and now includes the results from the combined Close the Gap scenario and extends the forecast to 2063.

It presents in a single graph the dramatic change in fortunes that could follow from the combined effect of the various scenarios. Such long-range forecasts are highly speculative but illustrate that from the middle of this century, Africa could actually start to catch up with the rest of the world. Although, even then Africa would have to maintain its positive trajectory for several decades to start achieving true convergence and, given the impact of technology and climate change, it will occur in a different world than the one we currently know.

If we were to consider progress in GDP per capita in each of Africa's five regions to a more reasonable 2040 time horizon, Central Africa performs the worst and Northern Africa the best. The most important reason for this divergence is the very rapid population growth in Central Africa compared to Northern Africa which also comes off a much higher income, education and health base. The Current Path forecast of economic growth will simply be insufficient to substantially improve the incomes of the rapidly growing populations in Central African countries.

There are many other considerations, too. Central Africa differs from other regions in that it does not have locomotive states (such as Nigeria in West Africa and South Africa in Southern Africa) where the size of a single national

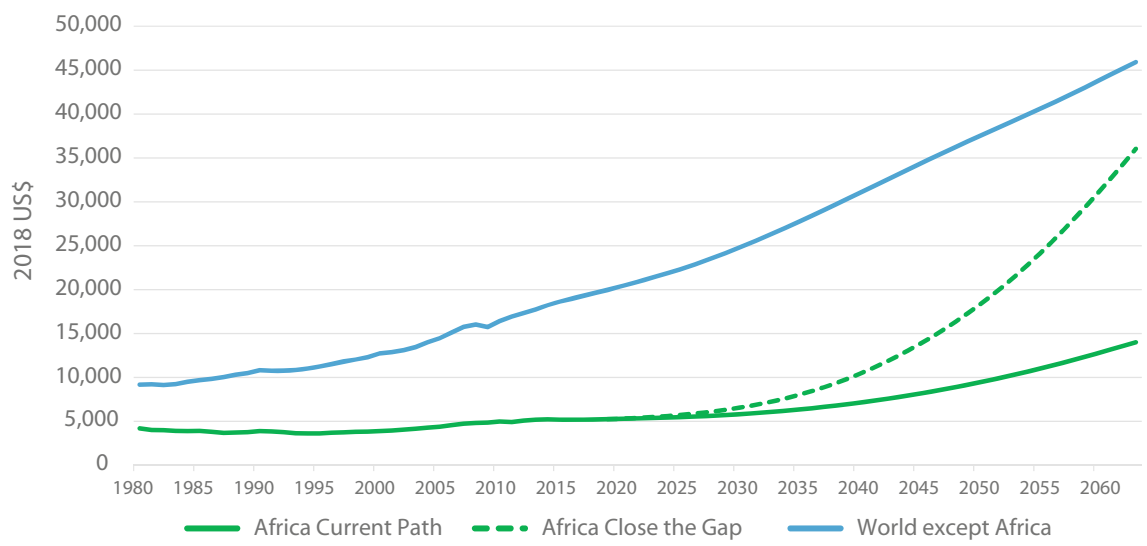

Fig. 16.1 GDP per capita: Africa vs World except Africa (Source IFs v7.45 initialising from World Bank World Development Indicators 2018) 
economy provides a sufficiently large market that could boost the region as a whole.

I have generally used the three standard World Bank country income classifications in this book as a kind of shorthand to present general trends among low, lower-middle and upper-middle-income countries. Figure 16.2 presents the average GDP per capita of the 24 low, 21 lower-middle and eight uppermiddle-income countries in Africa in 2018 and in 2040 in the Current Path forecast and then the 2040 forecast in the Closing the Gap scenario. The increase in column height reflects the improvement in GDP per capita from 2018 to 2040, first for the Current Path forecast and then for the Closing the Gap scenario.

In the Close the Gap scenario the average GDP per capita in 2040 in low-income Africa would be US\$5290 instead of US\$3340. In lower-middle income Africa it would be US $\$ 13,300$ instead of US\$9210, and in uppermiddle-income countries it would be US $\$ 22,260$ instead of US\$18,120.

The five countries that would gain the most in increases in average income levels when comparing the Current Path forecast with the Closing the Gap scenario are Mauritius, Botswana, Seychelles, Namibia and Gabon. The countries that gain the least are Niger, Central African Republic, Somali, Liberia and Burundi. All are low-income countries with high levels of conflict and instability.

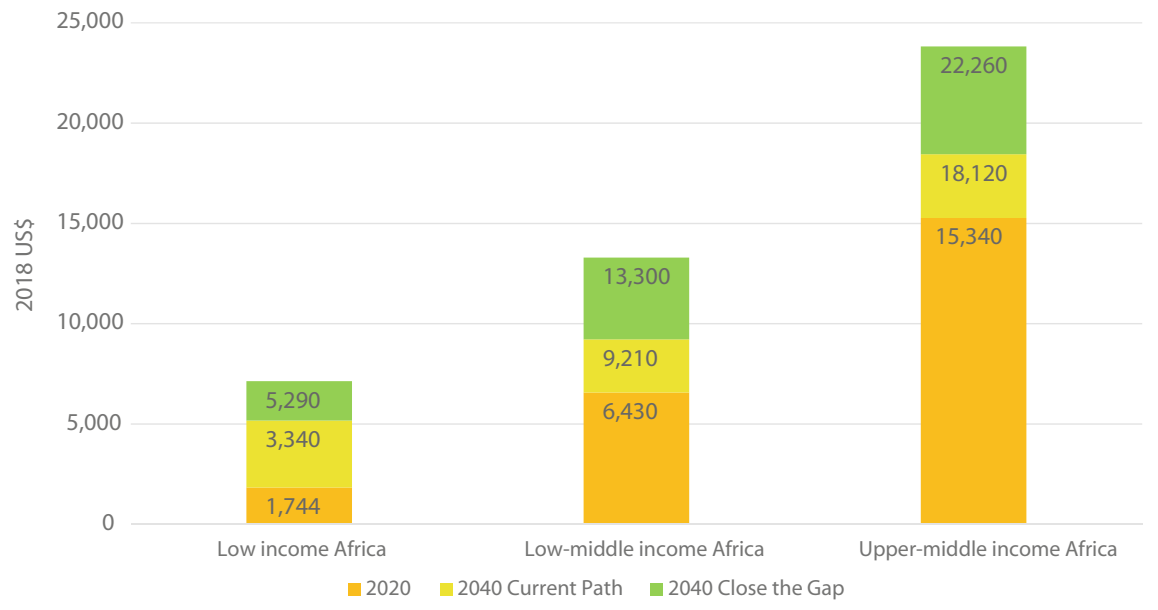

Fig. 16.2 GDP per capita in Current Path and Close the Gap in 2018 and 2040 (Source IFs v7.45 initialising from World Bank World Development Indicators 2018) 


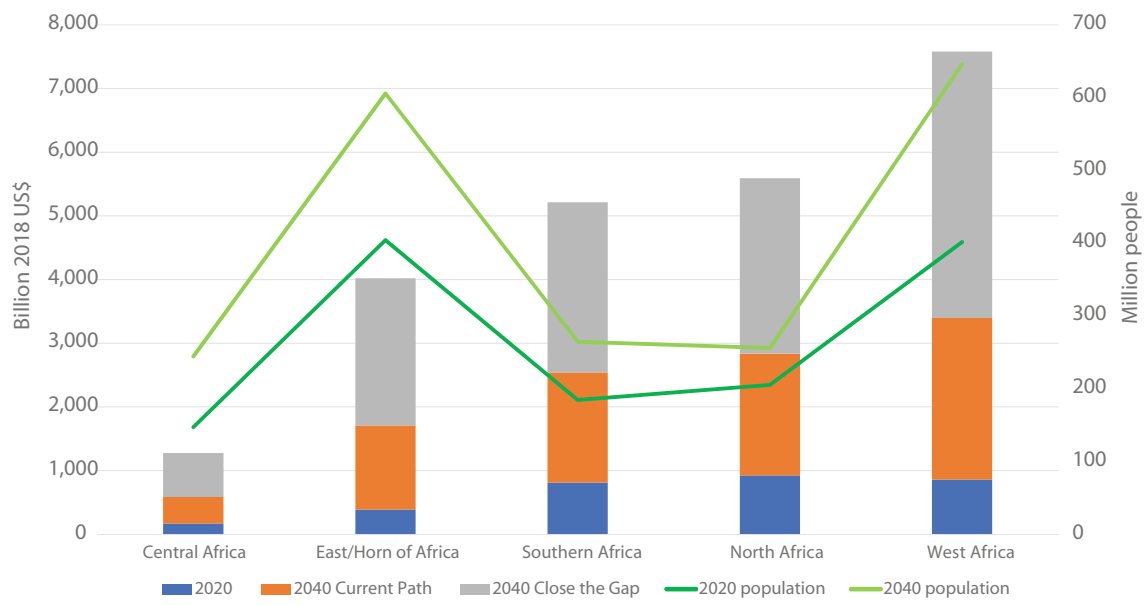

Fig. 16.3 Size of the regional economy in MER in Current Path vs Close the Gap scenario compared to population size (Source IFs v7.45 initialising from IMF World Economic Outlook 2017)

\section{Size of Economies in the Close the Gap Scenario}

Figure 16.3 is a bit more complicated. Using the left-hand scale it presents a stacked column that compares the size of the regional economies (Central, East/Horn, Southern, Northern and West Africa) in 2020 and then adds the increase from the Current Path and the Close the Gap scenario by 2040. That is similar to the presentation in Fig. 16.2. The line graph refers to the right-hand scale and presents the population in 2020 and 2040 for in the Closing the Gap scenario. Because of the impact of the demographic dividend scenario as well as improved education and health, the population numbers are lower than those for the Current Path forecast, which is not shown. ${ }^{2}$

By one measure, total population size, it's no wonder that West Africa has the largest economy since it also has the largest and most rapid population growth from 2020 to 2040. East Africa (including the Horn of Africa) has almost a comparably large population, but it's Closing the Gap economy is much smaller meaning the average citizen is much poorer. Central Africa has a relatively small economy compared to its population size and the economy experiences a very modest increase in size. Southern and North Africa do the best in terms of improvements in incomes given their more modest population growth.

\footnotetext{
${ }^{2}$ The population of Central Africa is 13 million smaller in Close the Gap in 2040 compared to the Current Path, 42 million in East/Horn of Africa, one million in North Africa, 12 million in Southern Africa and 28 million in West Africa.
} 
An important dynamic is the way in which the Demographic Dividend combines with the Rejuvenation in Education scenario to reduce total fertility rates quite rapidly. As a result, Africa's total economy could be US $\$ 12.6$ trillion in size in 2040 in the Close the Gap scenario instead of US\$7.9 trillion in the Current Path, despite (or because) of a population that is almost 100 million people smaller.

The impact accelerates over time. In 2063 in the Close the Gap scenario, Africa would have a population of 410 million fewer people, but its economy will be 2.5 times larger than in the Current Path forecast (US\$77 trillion instead of US\$30 trillion). If this were to occur, it would ensure a truly remarkable change in various other indices but then forecasts of such a long time horizon are quite shaky.

\section{Extreme Poverty in the Close the Gap Scenario}

The Close the Gap scenario has an even more impressive impact on poverty than on economic size and GDP per capita. Figure 16.4 provides a forecast of the number of extremely poor people in Africa using two income measures. The first uses US\$1.90 for all of Africa and the second uses a combination of US $\$ 1.90$ for low-income, US $\$ 3.20$ for lower-middle and US $\$ 5.50$ for uppermiddle-income countries. The reason and thinking behind these different measures are discussed in Chapter 7. The general trend is the same with both forecasts. The number of extremely poor people will expectedly remain

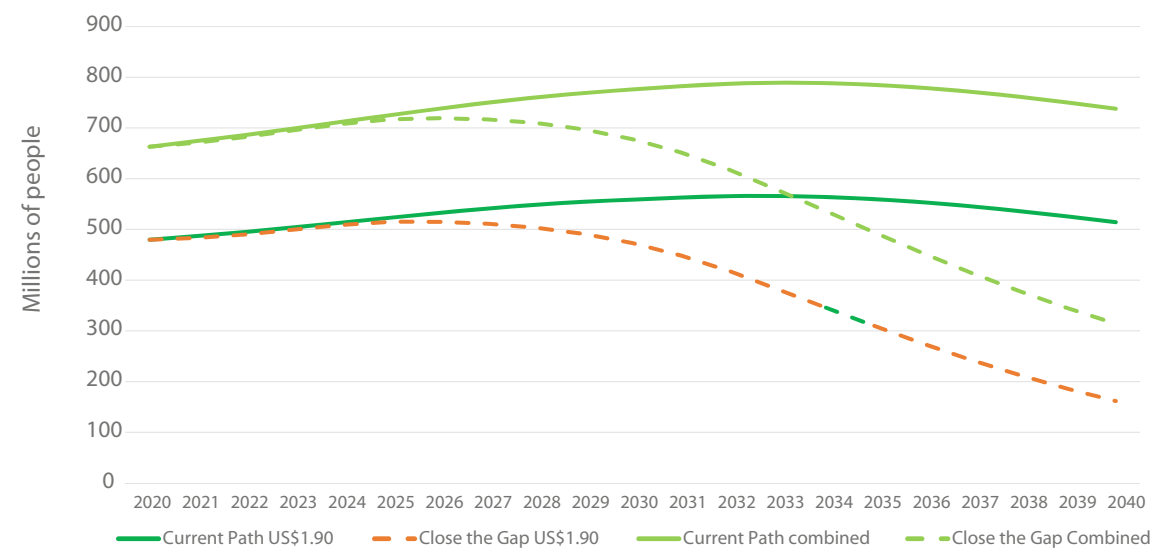

Fig. 16.4 Extremely poor people: 2020 to 2040 using US\$1.90 and other extreme poverty lines (Note that the combined scenario uses US $\$ 1.90$, US $\$ 3.20$ and US $\$ 5.50$ for low, lower-middle and upper-middle-income countries. Source IFs 7.45 initialising from World Bank, PovCalNet) 
constant out to 2040 in the Current Path forecast, but, whereas Africa either has 480 or 660 million extremely poor people in 2020 (depending upon the income definitions used), in 2040 this number could be reduced to 160 or 315 million people in the Close the Gap scenario, again depending upon the income definitions used.

It is clear that even in the Close the Gap scenario, Africa will miss the SDG target of eliminating extreme poverty by 2030 by a very large margin. Using the US\$1.90 extreme poverty line that is used to measure progress towards the SDG target, 475 million Africans will still be extremely poor. Or if presented as a portion of the total population, extreme poverty will decline from about 35 to $33 \%$ by 2030 and to $24 \%$ by 2040 . In the Closing the Gap scenario the numbers are $28 \%$ by 2030 and eight percent by 2040 .

Again a caveat: COVID-19 will negatively impact upon these forecasts since it seems inevitable that the global economy will contract sharply in 2020, perhaps longer as our understanding of the medium and long-term impacts are still unfolding.

Nevertheless, the scenario demonstrates that change is possible, and these changes represent a potential seismic shift in Africa's fortunes, as poverty is perhaps the single most important measure of improved well-being.

Table 16.1 presents the difference in millions of extremely poor people between the Current Path and Close the Gap in 2040 for four low-income, three lower-middle-income and two upper-middle-income countries. Again, these forecasts do not yet factor in the impact of COVID-19.

In Nigeria, the absolute number of extremely poor people will inevitably increase due to its rapid population growth and relatively slow economic growth rates, and the modelling used here suggests that trend cannot be reversed within the next two decades. Instead of 225 million extremely poor

Table 16.1 Impact on selected countries: millions fewer extremely poor people in 2040: difference between Current Path and Close the Gap scenarios

\begin{tabular}{ll}
\hline Country and relevant poverty line & Difference \\
\hline Ethiopia $(\$ 1.90)$ & -9 million \\
Democratic Republic of Congo $(\$ 1.90)$ & -68 million \\
Tanzania $(\$ 1.90)$ & -14 million \\
Nigeria $(\$ 3.20)$ & -59 million \\
Côte d'Ivoire $(\$ 3.20)$ & -5 million \\
Zambia $(\$ 3.20)$ & -10 million \\
Algeria $(\$ 5.50)$ & -9 million \\
South Africa $(\$ 5.50)$ & -11 million \\
\hline
\end{tabular}

Source IFs 7.45 initialising from World Bank, PovCalNet 
people in 2040 (Current Path), it would only have about 166 million (Close the Gap), which is about seven million more than currently.

Nigeria currently has around 210 million people. By 2040 Nigeria's population is forecast to be 360 million people on the Current Path but less than 350 million in the Close the Gap scenario as fertility rates decline, largely due to the impact of the Demographic Dividend scenario and better education. The percent of its population living in extreme poverty will therefore decrease from $76 \%$ in 2020 to $65 \%$ in the Current Path by 2040 , or only $48 \%$ in the Close the Gap scenario.

\section{Carbon Emissions in the Close the Gap Scenario}

The improvements in Africa's development prospects in the Close the Gap scenario come at a cost, even if it is a low cost by comparison to trends in the rest of the world. In the Close the Gap scenario, Africa would release about 120 million tonnes more carbon into the atmosphere by 2040 than in the Current Path. This may sound like a lot, but by 2040 annual global emissions would be about 10 billion tonnes, meaning that the additional emissions from Africa are quite modest. Had it not been for the reduction in Africa's total population as it progresses more swiftly through its demographic transition, the increase in annual carbon emissions would be larger. Noted in Chapter 15, most African countries have a unique opportunity to leapfrog a fossil-fuelled development model towards renewables.

Therefore in the Close the Gap scenario Africa would by 2040 contribute closer to seven instead of six percent to global carbon emissions. This means that the continent would have added around 900 million tonnes of additional carbon to the atmosphere (i.e. more than in the Current Path) over the preceding 20 years.

Still, the increased emissions in Africa occur at a time when the world needs to urgently reduce carbon emissions if it is to constrain global warming to below two degrees by the end of the century. Climate change is real and these forecasts indicate that even greater efforts are needed to transition to a greener economy and a sustainable planet, including in Africa. There are prospects for rapid improvements. For example a 2019 report by the International Energy Agency calculates that Africa could, using renewables, meet the 2040 energy demands of an economy four times larger than today's with only $50 \%$ more energy than today. ${ }^{3}$

${ }^{3}$ IEA, Africa's Energy Outlook 2019, Special Report. [Online] Available at www.iea.org/reports/africaenergy-outlook-2019. 


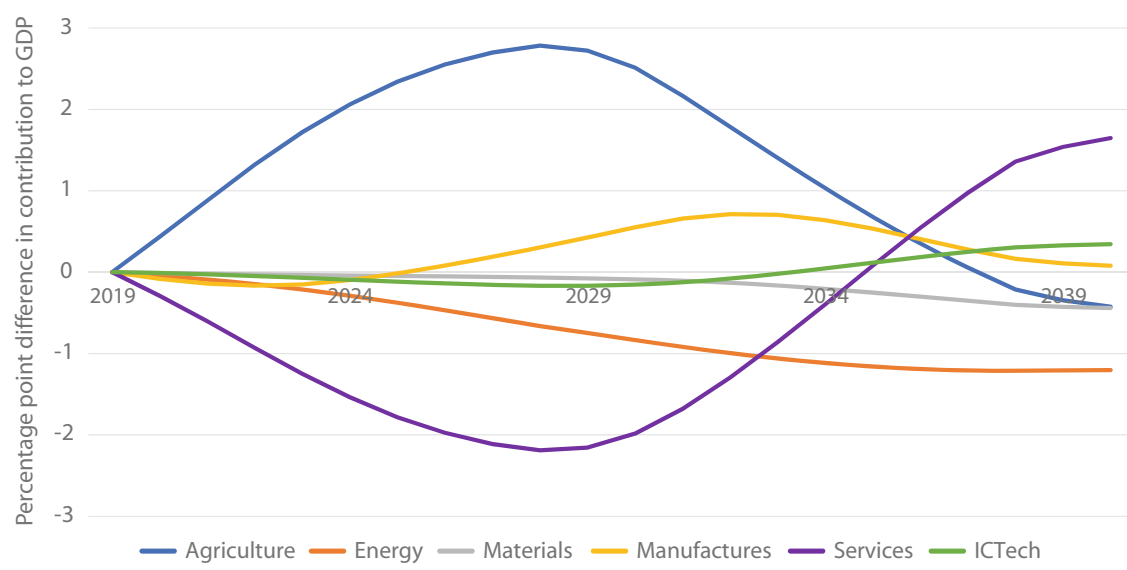

Fig. 16.5 Changes in value added to the economy in percent of GDP: Close the Gap vs Current Path for lower-middle-income Africa: 2019 to 2040 (Source IFs 7.45 initialising from IMF World Economic Outlook 2017 Note that his graph uses a fiveyear moving average)

\section{Structural Change of Economies in the Close the Gap Scenario}

The transitions modelled in this book are intended to emulate a process where Africa is able to reverse its growing commodities dependency and proceed on a pathway towards economic diversification. Many studies have sought to point to the potential, including that by African Growth Initiative at the Brookings Institution that have popularised the potential of 'industries without smokestacks'. ${ }^{4}$

To this end Fig. 16.5 presents the difference in the growth of the six economic sectors modelled in IFs, namely agriculture, energy, materials, manufactures, services and ICTech for Africa's 18 lower-middle-income countries when comparing the Close the Gap scenario with the Current Path. The comparison is presented as a percent change to GDP from 2020 to 2040. A similar graph could be drawn for low- and upper-middle-income country groups.

The scale on the left hand or y-axis of Fig. 16.5 indicates that the shifts are modest, at a maximum amplitude of below two and a half percent in either direction, but the impact of compound interest is such that these small changes have a large impact over time.

\footnotetext{
${ }^{4}$ Newfarmer, R., Page, J., and Tarp, F., 2018. Industries Without Smokestacks: Industrialization in Africa Reconsidered. WIDER Studies in Development Economics. Oxford University Press. [Online] Available at: https://www.wider.unu.edu/publication/industries-without-smokestacks-2.
} 
In fact, all sectors in Africa's 2040 economy will be bigger in the Close the Gap scenario than in the Current Path scenario. Whereas Fig. 16.5 presents the change in the composition of the economic structure of lower-middleincome African countries over time when comparing the Close the Gap with the Current Path scenario, Fig. 16.6 presents the size of each sector in 2018 with the Current Path and Close the Gap scenarios in 2040.

In this figure the changes to the size of each sector become evident. Note that whereas Fig. 16.5 is for lower-middle-income African countries, Fig. 16.6 is for Africa as a whole.

At a continental level, the Close the Gap scenario modestly constrains the growth of the services sector in favour of growth in the size of the agricultural sector until 2030. The Close the Gap scenario incentivises more growth in the manufacturing sector across the forecast horizon compared to the Current Path, while the contribution of the energy sector declines in the Close the Gap scenario compared to the Current Path.

Figures 16.5 and 16.6 reflect the structural transition of African economies to become more productive (the key contribution that flows from a larger manufacturing sector). In line with global trends the services sector will grow exponentially. It already constitutes the single largest share of the African economy although as I pointed out in Chapter 8 the traditional distinction between services, manufacturing and the like is really of limited value in the modern world.

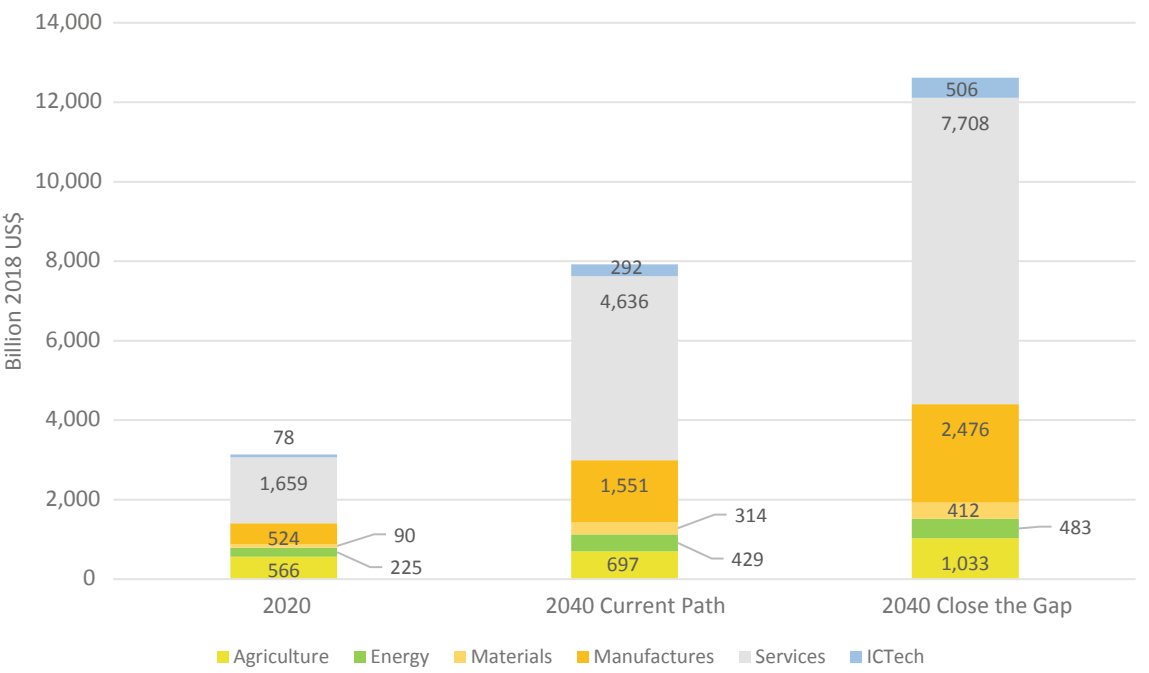

Fig. 16.6 Africa: value added by sector in billion US\$: 2020 vs 2040 for Current Path and Close the Gap scenario (Source IFs 7.45 initialising from IMF World Economic Outlook 2017) 
Even with the best will and good fortune it is unlikely that all countries in Africa would be able to achieve similar success in advancing across all dimensions. In addition, the type of reforms required to advance from low levels of development is quite different from that required at middle-income level. Eventually only individual country studies can provide an indication of the potential growth that a determined and far-sighted leadership can achieve.

\section{Comparing the Impact of Individual Scenarios Over Time}

The preceding sections presented the remarkable impact of the Close the Gap scenario on key indicators. In this section I compare the individual impact of the eleven scenarios on GDP per capita with one another.

My goal with this section is to illustrate the impact that different priorities could have, although much more detailed additional work is necessarily required at the national level. The analysis builds on the premise in Chapter 13 on governance that one of the greatest challenges is to ensure that governing elites will pursue national development, not personal or factional interests.

\section{Scenario Comparison Using Income Per Person as Key Indicator}

In addition to the fact that the impact of the various scenarios differs between low, lower-middle and upper-middle country groups, the impact also changes over time. So what contributes most to income growth for first decade (to 2030) for low-income countries may change during a second and third decade.

For example, in low-income countries agriculture and leapfrogging initially contributes the most to GDP per capita income growth. Actually the contribution from a Revolution in Agriculture is substantially higher than others. By 2040 agriculture still makes the largest contribution but starts to level off after that. By 2050, the implementation of the African Continental Free Trade Area is significantly larger than any other, followed by Leapfrogging, Made in Africa and Boosting Education. The increase in income from a Revolution in Agriculture is in a distant fifth place and waning.

A similar story holds for the group of lower-middle-income countries. Initially agriculture contributes most to income growth but loses momentum such that, by 2040, Made in Africa, the implementation of the African 
Continental Free Trade Area and Leapfrogging have overtaken agriculture in increasing incomes. Beyond 2040 the implementation of the African Continental Free Trade Area outpaces all others and continues to accelerate. By 2050 agriculture has fallen even further back in contributing to income growth. By mid-century the top five contributors are the African Continental Free Trade Area, Made in Africa, Leapfrogging, Boosting Education and Health (in that order).

The average differences between the impacts of the various scenarios across Africa's group of upper-middle-income countries are less pronounced, simply reflecting that as countries become wealthier, it becomes more difficult to achieve more rapid income growth from any set of interventions. That said, until around 2036 this group of countries gains most from the Leapfrogging scenario but thereafter the implementation of the African Continental Free Trade Area is most impactful.

So, because intra-African trade comes off such a low base, by 2050 the African Continental Free Trade Area scenario generally outpaced all other scenarios across all country income categories by a significant margin. It is for this reason that the African Development Bank, the UN Economic Commission for Africa, the World Bank and development economists are so excited about the progress being achieved with the implementation of the African Continental Free Trade Area and the potential that it holds for the future although events such as COVID-19 is sure to delay progress.

The contribution of the Demographic Dividend remains constant as the fourth or fifth most powerful scenario to 2050 and beyond. It serves as a timely reminder of the importance of the need for Africa to rapidly move through its demographic transition. Even then its impact is underplayed as the Demographic Dividend scenario is a kind of force multiplier on all other scenarios. It reduces the number of children that need to be educated (and increases the money available for those children already in school) and reduces the demand for basic infrastructure such as water and sanitation, for example.

The Social Grants scenario contributes the least to average income growth in all scenarios. That is not surprising as it largely deals with the symptoms of low growth and high inequality. Social protection against livelihood risks and to reduce the economic and social vulnerability of poor and marginalised groups is extremely important on a continent where the vast majority of the labour force does not have social insurance or related protection. However, it increases spending on recurring items rather than on investments for longterm growth. This is an important lesson for a country such as South Africa that has, since the end of apartheid, generally focussed on redistribution rather than on investing for growth. Although social protection is important, 
it should generally be seen as a short- to medium-term transitory programme while investing in appropriate education and hard infrastructure that would eventually unlock more rapid growth.

In the medium term, the provision of jobs in the formal sector can structurally shift inequality and reduce poverty at a much greater rate than education. But in the long term, improvements in relevant education are an indispensable requirement if countries are to go up the productivity curve. But it takes a very long time. By 2050 Boosting Education makes only the sixth largest contribution to income growth in low-income countries, fourth largest in lower-middle-income countries and third largest in upper-middleincome countries. In the very, very long-term education is the great leveller in providing improved opportunities to poor people and the relationship between better education and improved levels of income is strong. A rapidly growing low-income country such as Ethiopia cannot progress into low-end manufacturing (its stated goal) in spite of the large amounts of money that it spends in this sector since the language policies that it pursues in schools mean that kids do not understand what they are being taught by teachers who barely speak English themselves. Ethiopian children are currently taught in their mother tongue in grades 1-4, then in Amharic until, in grade 8, education switches to English. ${ }^{5}$ Tunisia and Algeria face similar challenges in trying to undo the damages that colonialism wreaked on their Arabic educational systems.

As I discuss in Chapter 6, the continent needs to change the way in which it rolls out education. The traditional methods of rote learning will not keep pace with the demand, never mind reducing the backlog in education and bold innovation and hard work is required in this domain. Governments need to fix education from the bottom upward, starting with ensuring literacy and investing in primary school enrollment and completion. Once progress is achieved in primary, the priority should shift to improving enrollment and completion in lower secondary schools; where after investment needs to shift to fixing, upper secondary and, eventually, tertiary education. Not all countries do this and some, such as Malawi, spend inordinate portions of their budget on tertiary education while neglecting primary and secondary education.

Generally quality is more important than quantity when it comes to education. Simply pushing children through school is not a solution if the education that is provided does not comprehensively and fundamentally

\footnotetext{
${ }^{5}$ Donnenfeld, Z., Cilliers, J., Kwasi, S., and Welborn, L., 2019. Emerging Giant Potential Pathways for Ethiopia to 2040. Institute for Security Studies. [Online] Available at: https://issafrica.org/res earch/east-africa-report/emerging-giant-potential-pathways-for-ethiopia-to-2040.
} 
address the basics of reading, writing and arithmetic, never mind the skills required for the fourth industrial revolution. And then much greater attention needs to be paid to vocational and technical training as opposed to the singular focus on academic teaching so evident across many African countries.

As with education, improvements in general indices of health take time and only translate very slowly into improved human capital where school pupils, students at technical colleges and universities, as well as workers, are better nourished and healthier, and therefore more productive.

The apparent limited impact of democracy also needs to be placed in context. In Chapter 13, I noted that democracy is not a prerequisite for economic growth at lower levels of development and that it should rather be viewed as a general or inherent good in its own right. Yet democracy is clearly the most desirable system of government. And eventually it does pay off. For example, countries with high levels of substantive (or liberal) democracy are generally richer than others and they are also healthier, particularly when using a key indicator such as rates of child mortality. Furthermore, citizens of democracies are generally happier. Without exception, people across the world aspire to have a say in who governs them, particularly in Africa where the alternatives have generally proven disastrous.

\section{Scenario Comparison Using Progress with the Human Development Index, Inequality and Extreme Poverty}

Using the Human Development Index as an alternative measure of progress, the Rejuvenation in Education scenario consistently performs better than any other scenario. It raises Human Development Index scores across the forecast horizon to 2040 and even beyond. Since the Human Development Index includes a substantial education weighting in its basket of indicators, this is an expected impact.

At the continental level the intervention on social grants (Chapter 7) and the scenario on a Revolution in Agriculture compete for the largest impact in reducing inequality across the forecast horizon, using the Gini index to 2040 for low- and lower-middle-income Africa. Upper-middle-income African countries do not experience the same reductions in extreme poverty from agriculture since it generally constitutes a much smaller component of their economies.

Another useful measure of progress that is used extensively in almost all chapters is rates of extreme poverty. The average results for low-income Africa are presented in Fig. 16.7, which compares the increase or decrease in poverty rates for selected scenarios with the forecast in the Current Path for 


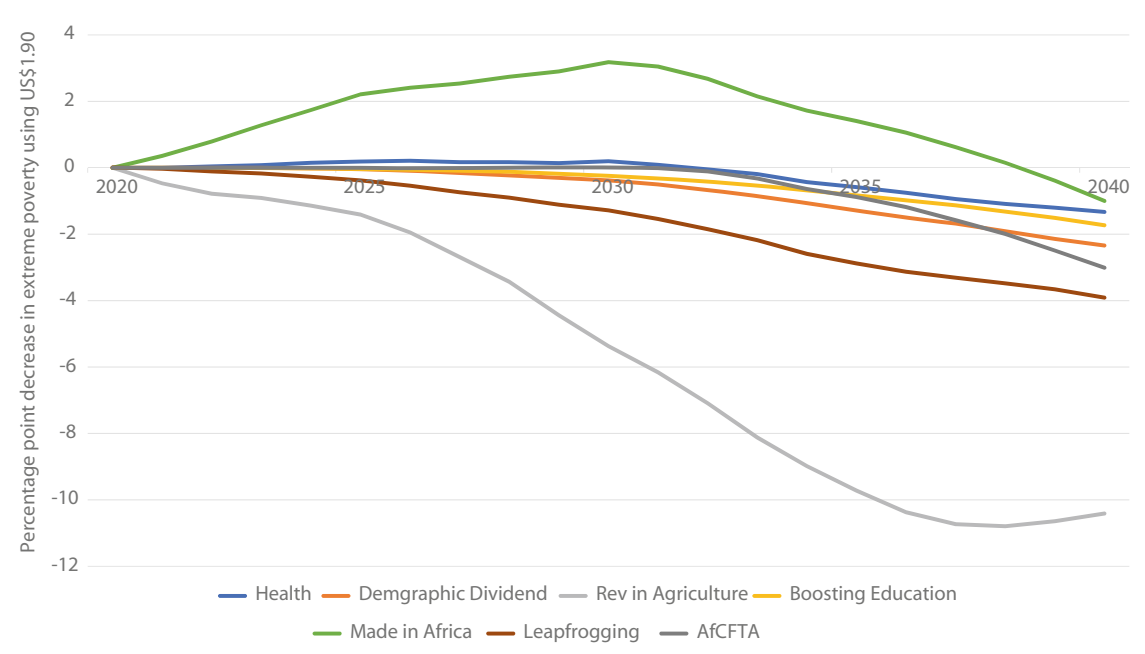

Fig. 16.7 Comparing the results of selected scenarios for lower-income Africa: percentage point reduction in people living below US\$1.90 per person per day (Source IFs 7.45 initialising from World Bank, PovCalNet)

Africa's current group of 24 low-income countries. The y-axis scale is therefore the percentage point difference between the scenario and the Current Path. Most visible is that the portion of Africans in extreme poverty initially increases by about three percentage points in the Made in Africa scenario. A manufacturing development pathway implies the use of scarce resources for more capital-intensive activities. The result is that poverty and inequality initially in low-income countries increase before quicker economic growth starts reducing both.

On the other hand, the Revolution in Agriculture scenario is significantly more powerful in reducing the percent of extremely poor Africans in lowincome countries than any other, in part because agriculture constitutes a significantly larger portion of the economy (on average about a third of GDP by value) than in lower-middle and upper-middle-income countries where it constitutes a quarter or less than eight percent.

Chapter 7 dealt with poverty and inequality and modelled the impact of social grants which has proven a particularly effective short to mediumterm strategy to reduce poverty and inequality. The provision of social grants is, however, a strategy that is more impactful for lower-middle and uppermiddle-income countries that cannot lever off a large agricultural sector as a means towards poverty reduction. The general tendency in these countries has, however, been to try and subsidise fuel and foodstuffs that have often locked governments into expensive programmes that they then find impossible to retreat from. It is for this reason that the World Bank and the 
IMF generally target the reduction of subsidies as a key component in their assistance strategies.

Poor countries generally have limited financial means to effect substantive transfers to the poor through social grant programs but it remains a strategy that is particularly well suited to poor countries that discover new mineral resources, such as the gas potential of Tanzania and Mozambique. In these countries the idea of ring-fencing natural resource income for distribution as cash grants rather than through subsidies on fuel and food that are more prone to wastage would have a salutary impact on levels of extreme poverty.

Figure 16.7 reinforces the traditional sequencing of development first discussed in Chapter 14, namely a governing elite that was strongly committed to economic growth that starts the developmental transformation process with a focus first on agriculture (that provides sufficient nutrition and food security), basic education and literacy (to improve human capital), and ensures a rapid demographic transition (through more rapid urbanisation and the provision of basic health care and modern contraceptives) while embarking on low-end manufacturing, even as the educational focus now shifts to secondary, vocational and tertiary education. Entry into manufacturing requires participation in regional value chains, the need to attract foreign direct investment and foreign companies with clear incentives for them to build local capacity and ensure technology transfer.

Africa needs to look at modern manufacturing and seek competitive advantages in areas such as ICT, food processing and horticulture that can play a role analogous to that played by manufacturing in East Asia. ${ }^{6}$ Much as economists struggle to explain the origins of economic growth, these broad outlines serve to frame a kind-of 'standard model' of development.

Given country differences, that model can only be described in the most general terms.

The role of government is crucial at low and middle levels of development. Then, as countries go up the income ladder economic growth in the twenty-first century becomes increasingly dependent on the role of the private sector as much in China and India as in Africa. Even then the role played by government remains crucial, although it now should shift to a predominantly regulatory and compliance function while ensuring inclusive growth by progressive tax policies and other measures of redistribution.

\footnotetext{
${ }^{6}$ This is the notion of 'industries without smokestacks' advanced by the Brookings Institution arguing in favour of sectors that are tradable, employing low and moderately skilled labor, having higherthan-average value added per worker, exhibiting capacity for technological change and productivity growth, and displaying evidence of agglomeration economies. See Newfarmer, R., Page, J., and Tarp, F., 2018. Industries Without Smokestacks: Industrialisation in Africa Reconsidered. WIDER Studies in Development Economics. Oxford University Press.
} 
Few facts illustrate the key role of private capital in Africa's development than the contribution that it could make to help fill Africa's energy shortfall. A 2019 report by the International Energy Agency calculates that cumulative investments of US $\$ 120$ billion per annum (or 2.4\% of gross domestic product [GDP]), will be needed between 2019 and 2040 to meet growing demand and improve access to modern energy services in Africa including electricity. ${ }^{7}$ That investment is clearly significantly beyond the ability of African governments without significant assistance from elsewhere.

As countries go up the manufacturing value chain, the spill overs from manufacturing facilitate and incentivise a more productive agricultural sector and the development of higher-end services like finance until, in some instances, services start to serve as the main engine of growth.

\section{What Is Possible? A Comparison with China}

Africa is young, rapidly urbanising and its population and economy will grow quite quickly. The levels of energy that are available on the continent remind one of China 25 years ago, but with important differences.

First, technology can allow Africa to leapfrog faster than even China, but the quality and nature of governance is likely to inhibit this potential. Compared to Africa China has an extraordinarily effective government. To date politics in Africa have often served as a constraint on development, and we have to find ways to make democratic accountability on the continent real.

While China is a single country with a centralised, authoritarian government, the African continent consists of 55 countries, each jealously guarding its sovereignty, and with large disparities in governance systems and traditions. Continental ambitions for regional economic integration are therefore likely to progress slowly, so regions such as Southern, West and East Africa should simultaneously move ahead with trade integration in their neighbourhood. As we saw in previous sections, the contribution from the African Continental Free Trade Area to growth, income and poverty alleviation is the biggest over longer time horizons and the same results will hold at sub-regional levels.

Second: Africa needs to take a leaf out of the Chinese textbook on empowering small-scale farming. Indeed, development is about empowering

${ }^{7}$ IEA, Africa Energy Outlook 2019. 
communities to become self-sufficient and independent from the helping hand of government and foreign donors alike.

Third, while the fast development of China was hugely aided by the country's very rapid (and politically driven) demographic transition, including its high peak demographic dividend, growth in Africa will be constrained by the slow pace of its demographic transition and the low levels of its peak demographic dividend.

The continent needs to engage in constructive debate about the extent to which its very youthful population serves as a drag on development and how it could encourage appropriate measures to reduce fertility rates in a responsible manner.

An important step would be to invest in improving the education levels of Africa's expanding labour pool, as well as to close the gender gap in education. And then some African countries such as Tunisia, Mauritius and Libya actually have to invest in maintaining their total fertility rate above the replacement level of 2.1 children per woman if they want to extend the time they will be lingering in the demographic sweet spot, or allow for inward migration. That is a challenge that China is currently grappling with.

Unlike Asia, where industrialisation and democratisation generally occurred sequentially, Africa has to balance the simultaneous challenges of democratisation and development on top of many others. This requires a fine balancing act and consummate political leadership.

\section{A Passion for Knowledge and Development}

On a structural level, many of Africa's challenges are rooted in the process of imposed state-formation that started with imperialism and lasted through the colonial period. Only very recently did the end of the Cold War release Africa into an international state-based system, when its own constituent states had not yet been consolidated. That is very different from the process of war against external forces through which the Westphalian state was established in Europe and from which we often draw our examples. ${ }^{8}$

Subsequently, Africa and its amalgamation of unconsolidated 'states in name' has been poorly served by elites who often appear to place politics and not evidence-based policy ahead of the continent's development. Eventually, neither Western donors nor China or India will develop Africa-only Africans can. To do this we need to understand where we come from but then

8The Peace of Westphalia signed in 1648 concluded the Thirty Year 'wars of religion' and is generally accepted as the start of the modern state system. 
also accept responsibility for shaping our future, manage our debt levels and invest responsibly.

Africa needs strong, developmentally minded governments that regulate, empower and support small and medium-sized businesses in the private sector, which is the primary wealth and employment creator in the twentyfirst century. In fact, experience from around the world highlights the need for growth policy to place particular emphasis on institutions and policies that promote strategic collaboration between the government and the private sector. ${ }^{9}$

The private sector in Africa is showing steady growth and doing so from the smallest informal trader to large multinationals. A recent study by McKinsey ${ }^{10}$ reveals that some 400 companies in Africa earn revenues of US $\$ 1$ billion or more and that nearly 700 companies have revenues greater than US\$500 million. Most have grown faster than their peers in the rest of the world in local currency terms, and most are more profitable than their global peers. Just over half are owned by Africa-based private shareholders, $27 \%$ are foreign-based multinationals and $17 \%$ are state-owned enterprises.

The continent also needs governments that consistently invest in knowledge creation.

In his epic study of economic history, the Norwegian scholar and economic philosopher Erik Reinert captures what lies at the heart of development. 'The global economy', he writes, 'can in many ways be seen as a pyramid scheme of sorts - a hierarchy of knowledge - where those who continually invest in innovation remain at the apex of welfare. ${ }^{11}$ Reinert points to the importance of 'going up the productivity and technology curve' generally a function of investments in research, development and expanding the manufacturing sector.

In a different context, the McKinsey Global Institute makes the same argument in concluding that 'all global value-chains are becoming more knowledge-intensive'. ${ }^{12}$ The associated response could take many forms like

\footnotetext{
${ }^{9}$ United Nations Economic Commission for Africa, 2013. Making the Most of Africa's Commodities: Industrializing for Growth, Jobs and Economic Transformation. Addis Ababa: Economic Commission for Africa; UNECA, 2013. Making the Most of Africa's Commodities: Industrialising for Growth, Jobs and Economic Transformation. Addis Ababa: United Nations. Economic Commission for Africa.

${ }^{10}$ Jayaram, K, Kassiri, O., and Sun, I. Y., 2017. The Closest Look Yet at Chinese Economic Engagement in Africa. McKinsey \& Company Report, June 2017. Available at: www.mckinsey.com/featuredinsights/middle-east-and-africa/the-closest-look-yet-at-chinese-economic-engagement-in-africa.

${ }^{11}$ Reinert, E. S., 2007. How Rich Countries Got Rich and Why Poor Countries Stay Poor. London: Constable, p 148.

${ }^{12}$ Lund, S., Manyika, J., Woetzel, J., Bughin, J., Krishnan, M., Seong, J., and Muir, Mac., 2019. Globalization in Transition: The Future of Trade and Value Chains. New York: McKinsey Global Institute, p. 1.
} 
developing modern industrial policies, but only deliberate efforts to unlock the promise of digitisation and the fourth industrial revolution will achieve this in the twenty-first century.

In the aftermath of the great global recession of 2008/2009, globalisation is again deepening, but growth and trade within regional trading blocs (as opposed to between these blocs) has become more important. ${ }^{13}$ Global value chains now appear to be shortening as production moves closer to consumers. This seems to be partly the result of efforts to improve the speed of getting goods to market, but is also a reaction to global tensions caused by a growing sense of nationalism like the very visible efforts by Europe and the USA to constrain technology transfer and competition from China. The impact of COVID-19 is likely to further accelerate this trend. Previously the costs of labour had been a deciding factor in the location of manufacturing, but in the last two to three decades non-labour costs-including the costs of managing complex global value chains-have increased in importance.

Regional value chains and localised production that is closer to the endmarket have become more attractive in advanced and emerging economies alike, with some even talking about doing manufacturing on demand based on technologies such as $3 \mathrm{D}$ printing. ${ }^{14}$ This is the emergence of the Alibaba model of decentralised, cottage-industry model of industrialisation referred to in Chapter 8.

Africa needs to integrate itself regionally and into the global economy to facilitate knowledge transfer, as China has done so successfully. It can do so by embarking on a digital and urban transition that has the combined potential to unlock other transitions in, for instance, education and the provision of basic infrastructure. Africans need to actively encourage foreign companies to invest and locate on the continent, as well as by attracting skilled foreigners. Technological knowledge transfer is crucial in addition to steadily expanding local content requirements to make sure that these companies are embedded in city and national value chains. Too narrow (or high) an area of specialisation often means that knowledge transfers do not occur. Over time, local value chains will allow African companies to also participate in and become part of international value chains.

Instead many African countries, Nigeria, Kenya and Zambia are three examples, specialise in what I refer to as the 'foreign ambush'. Their primary orientation is not to attract and nurture foreign business, but to trap them.

\footnotetext{
${ }^{13}$ McKinsey Global Institute, 2016. Digital Globalization: The New Era of Global Flows. New York: McKinsey \& Company, p. 3.

${ }^{14}$ De Backer, K., \& Flaig, D. 2017. The Future of Global Value Chains: Business as Usual or "a New Normal"? OECD Science, Technology and Industry Policy Papers, No. 41, pp. 8-9.
} 
Once a foreign company has been attracted by a liberal legal framework and fiscal incentives to invest, the rules are changed in an effort to extract greater profits and possibly even to benefit particular nationals or families. Nothing scares private investment more than uncertainty, and the threat of changes to their legal status or tax status is often a very large disincentive. The result is that those companies that do invest eventually capitulate and leave, as many South African (and other) companies have done in Nigeria, Kenya and Zambia. Then, to compound its general shoot-itself-in-the-foot policies, South Africa has been working hard since the end of apartheid to keep skilled foreigners at bay, making it as difficult as possible for them to obtain work permits and to invest.

In this regard, there is much that Africa can learn from China, which has perfected the art of setting up a subtler 'ambush' by requiring foreign companies to partner and transfer technology to local partners. In the process China, not the West, has emerged as the global manufacturing hub. It achieved these goals by making technology transfer and skills requirements law, including them in every agreement and then negotiating hard. China has set its intentions clearly to rival the USA as technology leader in a number of key areas including artificial intelligence and has been so successful that the West now scrambles to constrain its growth.

Many of Africa's post-independence efforts at industrialisation failed because of efforts to effectively create islands of technological sophistication and prestige projects in a sea of low-technology, informal economies. Without forward and backward linkages to the domestic economy, these projects were dependent on government subsidies and handouts in terms of access to foreign markets, for instance through the African Growth and Opportunity Act. Some of the recent investments in heavy-duty infrastructure (as opposed to basic infrastructure) threaten to replicate these mistakes.

When these agreements came to an end, the investments proved unsustainable and the company inevitably folded or left. It is for the same reason that highly capital intensive projects like gas and petroleum extraction projects provide little spillover effect to the wider economy in northern Mozambique, in Angola, Nigeria, Equatorial Guinea and Gabon. All provide a stream of money to state coffers and the fight for control of that money often determines who governs. But oil or gas income on its own does not develop a country. Above all, it needs appropriate government policy, ethical leadership and oversight that unlocks the one thing we have in abundance, our human capital. 
Eventually the transformation of Africa is less about grand schemes and ambitions (of which there have been many) and more about the mundane functions of improving food security through land reform and support of small-scale farming; ensuring a hassle-free and facilitative investment environment; holding one another to account; and facilitating foreign investment in clear terms. It requires a technical and bureaucratic process, where governments have to meticulously go through every single impediment that deters or inhibits innovation, entrepreneurship and doing business. This is about a government that gets behind success, offering support and helping to facilitate a potential growth sector that is already showing potential and doesn't merely shovel money in that direction.

Planning long-term requires policy certainty, and there are many challenges in this domain as civil resistance campaigns against dictators and lifetime presidents mount. For investment, as opposed to war profiteering, policy predictability is a prerequisite. Stability is also important, and, as I explored in Chapter 13, instability has become characteristic of an increasingly small number of countries.

\section{In Conclusion}

Development is about countries empowering themselves and learning how to help themselves. It is not about handouts and there is no magic wand. The absence of a sense of nationhood is a major distraction in many African countries, and it is a sad reality that many nations that have done well in recent times (Korea, Ethiopia, Rwanda, South Korea, Taiwan and China) did so only after suffering a national trauma like war or genocide.

This book presented a host of policy recommendations that seek to advance the development of Africa. The general result that emerges from the analysis is to work from the bottom upward - to fix the basics. For example the need to invest in basic infrastructure such as electricity, sanitation, water and roads and literacy and primary education, and to invest in empowering and helping small-scale farmers and businesses to improve productivity. Leapfrogging should be seen within this context-how can Africa benefit from new technologies to do things more rapidly and cheaply, such as using digital ID systems and electronic payments systems to improve the capacity of governments to deliver more effective programs, and to provide electricity to their citizens through decentralised mini-grids using renewables. Access to electricity and the global village (through access to the internet) offers huge potential to embark on a rapid digitisation process and its potential as a 
key enabler was explored in the Leapfrogging scenario. ${ }^{15}$ Large infrastructure projects are important, but the trade-off is really to make sure that there are, first, enough paved roads before investing in hugely expensive railway lines unless these are to service specific heavy-duty exports such as iron ore.

Underlying much of this is the need for Africa to progress more swiftly through its demographic transition by reducing fertility rates and more rapid but planned and deliberate urbanisation. Although Africa is urbanising it is generally not planned or maximised. Some countries are already largely urban but the East/Horn of Africa is probably the most rural region in the world.

The solutions to Africa's urbanisation trap are well documented. The first is urban land rights. Without clear legal rights and a formal property market that allows for the secure transfer of property rights, land cannot serve as a tradeable asset and investments are limited to those done by the state. Digitisation and modern technology allows Africa to do much of this more rapidly than is the case historically anywhere else.

The second is the early installation of infrastructure like roads, water, sewage and electricity connections at low levels of density as was done in China. And it serves as an opportunity to build climate-resilience and to manage the spread of infectious diseases such as COVID-19. Thirdly, cities develop if they are able to formalise business practices, hence increase the tax base and improve efficiencies and productivity. Cities that are overcrowded and congested also have higher costs of production and are generally unable to produce internationally traded goods. ${ }^{16}$

Basic infrastructure must largely be put in place before people arrive. Once an informal settlement has reached the size of Khayelitsha in Cape Town or Kibera in Nairobi, it is very difficult to uproot populations to install plumbing or build proper roads. Providing water and sewer connection for half a million people is a challenging enough task. However, if all these people must be relocated to provide that infrastructure, it is not only significantly more expensive, but also more difficult on a political level. In the absence of clean water and adequate sanitation facilities, it remains to be seen to what extent modern medicine can continue to offset the absence of basic

\footnotetext{
${ }^{15}$ United Nations Economic Commission for Africa, 2019. Fiscal Policy for Financing Sustainable Development in Africa. Addis Ababa: Economic Commission for Africa, p. xiii.

${ }^{16}$ Collier, P., 2016. African Urbanisation: An Analytic Policy Guide. London: International Growth Centre, pp. 23-25. On p. 26 he writes as follows on the issue of 'active city government': 'Five types of government action are required: land registration; provision of public infrastructure and services for transport; provision of public social goods and services for decent quality of life; enforcement of those private behaviours which are socially beneficial but not individually advantageous; coordination of those private decisions which are interdependent; and revenue generation through taxation and debt to finance these activities'.
} 
infrastructure that traditionally provided for a reasonable standard of healthy living.

Urbanisation, digital transformation and electrification should be adopted as deliberate strategies towards providing basic services, better education, improved health care, educational opportunities, economic growth and mitigating the impact of climate change. The digital transformation of Africa will require huge investment to make the internet and the web-accessible but there is really potential in initiatives such as that from SpaceX or OneWeb that promise global, satellite internet coverage within the next few years. ${ }^{17}$

Current forecasts would indicate that the rise of India could again see a global resources boom starting within the next decade. Much as African economies need to diversify, it is unlikely that this will be possible by then. Nor is it a given that Africa will be the region to benefit most from this boom for, according to the Fraser Institute, much of Africa ranks near the bottom in their annual survey of mining and exploration attractiveness with Kenya and Mozambique the least attractive and Ghana and Mali the most attractive. ${ }^{18}$

Resource extraction can provide an opportunity to invest in the efforts required to transform Africa's economies and education systems for greater productivity. However, this is only possible if Africa uses that income and opportunity as a foundation and opportunity for structural economic transformation - going up the productivity value chain.

For countries to develop and grow they need to gain and invest in knowledge creation, which must be done by investing in education through knowledge transfers and by a focus on spurring innovation and entrepreneurship, as well as domestic research and development.

Apart from everything else, African countries need a modern leadership that is able to connect with the aspirations of its youthful population; one that is prepared to move on after a set term and to look to the future, not the past. They need a leadership attuned to tomorrow, not fixated on yesterday, and that rely on evidence-based policymaking, not ideology. That is the essence of the call by Nelson Mandela ${ }^{19}$ to no longer 'seek to place

\footnotetext{
${ }^{17}$ Moya, A., 2019. How Africa Can Tap into SpaceX's Starlink Satellites. itWeb. [Online] Available at: https://www.itweb.co.za/content/KWEBbvyaw43vmRjO.

${ }^{18}$ Investment decisions are not only based on pure mineral potential but on policy certainty and confidence in a policy regime that will remain stable. Policy factors account for approximately $40 \%$ of investment decisions. Regionally only Latin America and the Caribbean fares worse than Africa. Stedman, A., \& Green, K. P., 2018. Annual Survey of Mining Companies: 2017. [Online] Available at: https://www.fraserinstitute.org/studies/annual-survey-of-mining-companies-2017.

${ }^{19}$ Mandela, N. R., 2002. Address by Nelson Mandela at Gala Banquet Celebrating Africa's 100 Best Books of the 20th Century, 23 July. Available at: www.mandela.gov.za/mandela_speeches/2002/020 723_books.htm.
} 
blame for our condition elsewhere or to look to others to take responsibility for our development', but to become the masters of our own fate.

These then, are the challenges and opportunities that confront Africa today, as it aims to Close the Gap with the rest of the world.

\section{Further Reading}

Africa Growth Initiative, Brookings, online resource. https://www.brookings.edu/ project/africa-growth-initiative/.

Banerjee, A.V., and Duflo, E. 2020. How Poverty Ends: The Many Paths to Progress-and Why They Might Not Continue. Foreign Affairs, January/February.

Institute for Security Studies, African Futures \& Innovation, online resource. https://issafrica.org/topics-regions/search?topics=218\&regions.

OECD, Shaping Africa's Urban Future Together, online resource. http://www. oecd.org/africa-urbanisation/?utm_source=Adestra\&utm_medium=email\&utm_ content=Digital $\% 20$ Report $\% 3 \mathrm{~A} \% 20$ Africa\%20Urbanisation\&utm_campaign= What $\% 27$ s\%20New\%20-\%2014\%20February\%202020\&utm_term=demo.

Open Access This chapter is licensed under the terms of the Creative Commons Attribution 4.0 International License (http://creativecommons.org/licenses/by/4.0/), which permits use, sharing, adaptation, distribution and reproduction in any medium or format, as long as you give appropriate credit to the original author(s) and the source, provide a link to the Creative Commons license and indicate if changes were made.

The images or other third party material in this chapter are included in the chapter's Creative Commons license, unless indicated otherwise in a credit line to the material. If material is not included in the chapter's Creative Commons license and your intended use is not permitted by statutory regulation or exceeds the permitted use, you will need to obtain permission directly from the copyright holder. 